\title{
Implementación de la estrategia ambiental Producción más Limpia (PmL) para el proceso productivo de la microempresa Productos Lácteos del Norte
}

DOI: https://doi.org/10.33262/ap.v3i2.2.57

\begin{abstract}
(c) (1) (8)(2)
BY NC SA

Implementation of the environmental strategy Cleaner Production (CP) for the production process of the microenterprise Productos Lácteos del Norte
\end{abstract}

María Soledad Núñez Moreno. ${ }^{1}$

\begin{abstract}
.
This article aims to implement the environmental strategy Cleaner Production (CP) in the productive process of the small company Productos Lácteos del Norte, through the application of this efficient management strategy, in order to obtain economic savings and minimize the environmental impact for the benefit of industrial sustainability. The article initially makes a brief literary review of $\mathrm{CP}$, its importance, benefits and legal framework. Subsequently, 4 phases were created to implement the strategy, these phases were structured based on the CP Application Guide in the Dairy sector of the CPML of Nicaragua and the General Technical Guide of CP of the CPTS of Bolivia. Finally, the $\mathrm{CP}$ environmental strategy was implemented in the small company, through the development of the phases of planning and organization, re-evaluation, evaluation and feasibility study. In the results of the feasibility study, indicators were obtained of: energy consumption of $115,3 \mathrm{~W} \cdot \mathrm{h} / \mathrm{t}$ of cheese, which is within the recommended value; water consumption of $9,06 \mathrm{~L}$ of water/kg of milk, which is outside the allowed range. The CP environmental strategy was implemented in the small company, however, the execution of the analysis of proposals in the medium and long term will have to be carried out for its consolidation.
\end{abstract}

1 Escuela Superior Politécnica de Chimborazo, Facultad de Ciencias, Riobamba, Ecuador, solenu0408@gmail.com, ORCID: https://orcid.org/0000-0001-7526-9870 
Keywords: Cleaner production, Kneaded cheese $\mathrm{CP}$, dairy production process, $\mathrm{CP}$ environmental strategy, CP implementation.

\section{Resumen.}

El presente artículo tiene por objetivo implementar la estrategia ambiental Producción más Limpia (PmL) en el proceso productivo de la microempresa Productos Lácteos del Norte, mediante la aplicación de esta estrategia de gestión eficiente, para obtener un ahorro económico y minimizar el impacto ambiental en beneficio de la sostenibilidad industrial. En el artículo inicialmente se realiza una breve revisión literaria de PmL, su importancia, beneficios y marco legal. Posteriormente, se crearon 4 fases para implementar la estrategia, estas fases fueron estructuradas en base a la Guía de Aplicación de PmL en el sector Lacteo del CPML de Nicaragua y la Guía Técnica General de PmL del CPTS de Bolivia. Finalmente, se implementó la estrategia ambiental PmL en la microempresa, mediante el desarrollo de las fases de planeación y organización, re evaluación, evaluación y estudio de factibilidad. En los resultados del estudio de factibilidad se obtuvieron indicadores de consumo de energía de $115,3 \mathrm{~W} \cdot \mathrm{h} / \mathrm{t}$ de queso, que está dentro del valor recomendado; gasto de agua de 9,06 L de agua/kg de leche, que esta fuera del rango permitido. Se implementó la estrategia ambiental PmL en la microempresa, sin embargo, la ejecución del análisis de propuestas a mediano y largo plazo tendrá que ser realizado para su consolidación.

Palabras claves: Producción más Limpia, PmL queso amasado, proceso productivo lácteo, estrategia ambiental PmL, implementación PmL.

\section{Introducción}

La industria láctea tiene un gran impacto socio económico en el Ecuador, además de, una gran tradición, tal es el caso, que en el año 2017 se produjo 36.260 .925 kilos de este producto. Sin embargo, pese a que se produce leche en el transcurso de todo el año y a la liberación que existe en su mercado, no se ha logrado aprovechar la producción existente, debido a muchos factores que han perjudicado al sector como los intermediarios, el contrabando, las importaciones, entre otros (Pardillos, 2020) (Alvarado, 2018).

Si bien es cierto que el consumo per cápita de leche en Ecuador es de 90 litros anuales, lo cual es inferior a lo recomendado por la Organización Mundial de la Salud que es 150 litros al año, la demanda de queso, producto derivado de la leche, está aumentando, tendencia que espera mantenerse hasta el año 2024, ya que, alrededor de un millón y medio de personas en el país viven directa o indirectamente de la producción de lácteos, generando en ventas 1600 millones de dólares anuales (Pardillos, 2020) (Alvarado, 2018). 
La Tabla 1 muestra los porcentajes de productos obtenidos a partir de la producción lechera en el Ecuador, siendo la producción de queso la categoría láctea a la que más leche se destina, con una cifra del 31\%, sobre el total en 2017 (Pardillos, 2020) (Alvarado, 2018).

Tabla 1. Porcentajes de productos a partir de la producción lechera del Ecuador (Alvarado, 2018)

\begin{tabular}{lc}
\hline \multicolumn{2}{c}{ Destino de la producción lechera } \\
\hline Queso & $31 \%$ \\
Leche en funda & $27 \%$ \\
Leche en cartón & $20 \%$ \\
Leche en polvo & $11 \%$ \\
Yogurt & $10 \%$ \\
Otros & $1 \%$ \\
Total & $100 \%$ \\
\hline
\end{tabular}

Desde el año 2017 hasta la actualidad el mercado del queso en el Ecuador está en fase de crecimiento productivo y económico. Esto se debe a dos razones, la mayor demanda de queso por parte de los consumidores ecuatorianos, y por el Acuerdo Multipartes entre Ecuador con la Unión Europea que entró en vigor en 2017 (Pardillos, 2020).

Según el Centro de la Industria Láctea de Ecuador (CIL), entre los años 2006 a 2017, el consumo promedio per cápita de queso se ha incrementado de 0,75 kilos a 1,7 kilos, y en los últimos cinco años el precio medio ha subido en un 3,42\%. En el año 2019, el queso maduro se comercializaba a un precio medio de 13,14 USD/kilo, mientras que el queso suave a un precio medio de 8,42 USD/kilo (Pardillos, 2020) (Revista Líderes, 2015).

En la provincia de Carchi existen cantones como Tulcán, Montúfar, Julio Andrade, Espejo, entre otros, en donde las microempresas lácteas producen queso amasado, siendo en el cantón Tulcán donde se encuentra la microempresa Productos Lácteos del Norte con la producción de queso amasado. La producción en esta provincia supera los 300 mil litros diarios de leche, de los cuales, más de 20 mil se destinan a la elaboración de queso, lo que representa 5 mil quesos diarios. Esta elevada producción genera aguas residuales, residuos sólidos y consumo energético. Por tal motivo la microempresa Productos Lácteos del Norte ha decidido implementar la estrategia ambiental Producción más Limpia (PmL) como un compromiso responsable con el medio ambiente.

Bajo este contexto el Centro Ecuatoriano de Eficiencia de Recursos y Producción más Limpia, sin fines de lucro, incentiva y contribuye con el progreso de la productividad y el medio ambiente en el país, a través de la estrategia PML. La implementación de la estrategia ambiental PmL propone oportunidades de mejora, disminución de costos y aumento en la productividad, mediante la implementación de buenas prácticas de gestión en los procesos productivos, sin necesidad de invertir grandes cantidades de dinero. (Escaño, 2010). 
La microempresa Productos Lácteos del Norte en vista de la normativa ambiental vigente y en contribución a la solución de la problemática ambiental actual busca alternativas para el aprovechamiento eficiente de los recursos e insumos, con el propósito de alcanzar un ahorro hídrico, energético y económico en sus procesos, por lo que se ha optado por la implementación de la estrategia PmL.

El desarrollo de este proyecto busca contribuir al mejoramiento del desempeño ambiental y productivo a lo largo de la cadena de producción de la microempresa, mediante la implementación de la estrategia PmL.

En el desarrollo de este proyecto de investigación se ha seguido una metodología descriptiva-explicativa, fundamentada en la revisión y análisis de fuentes bibliográficas como las desarrolladas por Pardillos (2020) El mercado del queso en Ecuador, Alvarado (2018) Estudio de Mercado Sector de la leche en el Ecuador, Centro de Producción más Limpia de Nicaragua (2008) Guía de Aplicación de PmL en el sector Lácteo, Centro de Promoción de Tecnologías Sostenibles (2005) Guía Técnica General de PmL, entre otras.

\section{Revisión literaria}

La Producción más Limpia (PML) es una estrategia para la utilización eficiente de recursos como el agua, energía, materias primas y desperdicios. Su importancia radica en ser una estrategia preventiva con un enfoque proactivo, beneficiando al mejoramiento continuo de los procesos productivos. En el Ecuador existen entidades estatales y privadas que la promocionan siguiendo el respectivo marco legal.

\section{Producción más Limpia (PML)}

El concepto de Producción más Limpia lo utilizó por primera vez el Programa de Naciones Unidas para el Medio Ambiente, en el año 1989, y fue definido como una estrategia ambiental preventiva e integrada a los procesos, productos y/o servicios para aumentar la eficiencia global y reducir los riesgos para los seres humanos y el medio ambiente (Rodríguez et al., 2019) (Tinoco y Armijo, 2019) (Nunes et al., 2019).

La PML "es un concepto novedoso que evita o minimiza los desechos y contaminantes aun antes de que estos sean generados, obteniéndose como efecto inmediato una reducción en el consumo de materias primas, agua y energía." (Varela, 2003, pág.4)

\section{Importancia de la estrategia ambiental Producción más Limpia}

Existen varios instrumentos que buscan promover la gestión ambiental empresarial, uno de ellos es la PmL, la cual, brinda tanto beneficios ambientales como económicos. Su importancia radica en ser una estrategia preventiva, con un enfoque más proactivo que reactivo en la solución de problemas, además de, encontrarse acorde a los principios de desarrollo sostenible (Nunes et al., 2019) (Van Hoof et al., 2008) (Hens, 2018). 
El Banco Mundial señala la importancia de aplicar la estrategia PmL en la cadena de producción, ya que con su aplicación se puede reducir la contaminación de un $20 \%$ al $30 \%$, sin necesidad de una alta inversión (Van Hoof et al., 2008) (Odes, 2002).

\section{Beneficios de la estrategia ambiental Producción más Limpia}

Los principales beneficios de aplicar la estrategia ambiental PmL son el ahorro de agua y luz, reducción de costos de operación, ahorro de materia prima, mejora continua de las condiciones laborales, eliminación de materia prima dañina o tóxica, reducción y manejo adecuado de residuos, lo que contribuye al mejoramiento continuo de los procesos de producción o la prestación de servicios (Rodríguez et al., 2019) (Uguña, 2010) (Hens, 2018).

\section{Marco legal}

La microempresa Productos Lácteos del Norte cumpliendo con las leyes del territorio ecuatoriano fundamenta su marco legal, para la implementación de PmL, en las siguientes normativas jurídicas: Constitución de la República del Ecuador. Ley de Gestión Ambiental, Ley No. 37. Ley de prevención y control de la contaminación ambiental. Código Orgánico Ambiental (COA). Reglamento de Seguridad y Salud de los Trabajadores y Mejoramiento del Medio Ambiente de Trabajo. Ordenanza que establece las Políticas Ambientales del Gobierno Provincial del Carchi, del 24 de febrero de 2010, entre otros.

\section{Metodología para implementar la estrategia ambiental pml}

La estructuración de la metodología para implementar la estrategia ambiental PmL fue en base a la Guía de Aplicación de PmL en el sector Lacteo del CPML de Nicaragua (2008) y la Guía Técnica General de PmL del CPTS de Bolivia (2005). Su estructuración consta de cuatro fases: planeación y organización, pre evaluación., evaluación y estudio de factibilidad.

\section{Fase 1 de planeación y organización}

El objetivo de esta fase fue crear las condiciones necesarias para realizar el modelo de PML en la planta. En esta etapa se siguió los siguientes pasos:

Primero, se llevó a cabo una reunión con el gerente de la microempresa para tener acceso a las instalaciones, recopilar información y pedir la colaboración de los trabajadores para implementar la estrategia ambiental PML.

Segundo, se elaboró un cronograma para la implementación de la estrategia ambiental PML. 


\section{Fase 2 de pre evaluación}

El objetivo de esta fase fue el de tener un diagnóstico general de la situación actual de la microempresa. Para esto se siguieron los siguientes pasos:

Primero, se recopiló la información general de la microempresa para conocer las actividades que se realizan, se elaboró diagramas de flujo del proceso productivo, se dio a conocer su ubicación y se capacitó a los trabajadores sobre la estrategia PML.

Segundo, se observó el proceso productivo para realizar un respectivo análisis.

Tercero, se realizó tablas elaboradas para registrar materiales, insumos, consumo de agua y luz y cantidad de residuos, también en esta etapa se realizó el ensayo físicoquímico y microbiológico de las aguas residuales provenientes del proceso productivo.

Cuarto, se realizaron encuestas a los habitantes donde se encuentra la microempresa para conocer el impacto que generan los desechos industriales del proceso productivo.

\section{Fase 3 de evaluación}

El objetivo de esta fase fue conocer de manera cuantitativa el consumo de agua, energía y generación de residuos, además de, proponer opciones de Producción Más Limpia. Se realizaron los siguientes pasos:

Primero, se ordenó la información recolectada y se evaluaron los datos cuantitativos, para este paso se consideró las planillas de consumo de agua y luz, y los datos del consumo de materiales, insumos, agua y energía, de cada etapa del proceso productivo.

Segundo, con los datos recolectados se procedió a la elaboración de balances para conocer la cantidad de insumos y materia prima utilizados en el proceso y la producción procesada.

Tercero, consolidada la información de la microempresa y sus procesos productivos se realizó el análisis FODA (Fortalezas, oportunidades, debilidades y amenazas).

Cuarto, a partir del análisis FODA se identificaron las posibles oportunidades para la implementación de la estrategia ambiental PML.

\section{Fase 4 de estudio de factibilidad}

El objetivo fue analizar las oportunidades de la estrategia PML para conocer su viabilidad en términos técnicos, económicos y ambientales. En esta etapa se siguió los siguientes pasos:

Primero, se realiza un análisis de producción, consumo de energía, consumo de agua, aguas residuales, producción de residuos y propuestas para la implementación de la estrategia PmL. 
Segundo, se dio a conocer los resultados del estudio de factibilidad para establecer la viabilidad de la implementación de la estrategia ambiental PmL.

\section{IMPLEMENTACIÓN DE LA ESTRATEGIA AMBIENTAL pmI PARA EL PROCESO PRODUCTIVO DE LA MICROEMPRESA}

La implementación de la estrategia ambiental PmL para el proceso productivo de la microempresa Productos Lácteos del Norte, se la realizo en base a la metodología estructurada en el ítem 3 de esta investigación.

\section{Fase de planeación y organización}

En esta fase se realizó una reunión con el gerente donde se le informo de los beneficios a corto, mediano y largo plazo, de implantar la estrategia PML a la microempresa, también se presentó un cronograma de fases para su implementación.

\section{Fase de pre evaluación}

La fase de pre evaluación está integrada por la información de la microempresa, el proceso productivo para la elaboración del queso y la prueba de laboratorio a las aguas residuales.

\section{Información de la Microempresa}

La información general de la microempresa Productos Lácteos del Norte perteneciente a la ciudad de Tulcán, provincia de Carchi, del territorio ecuatoriano, se muestra en la Tabla 2.

Tabla 2. Información de la microempresa Productos Lácteos del Norte

\begin{tabular}{cc}
\hline \multicolumn{2}{c}{ Microempresa Productos Lácteos del Norte } \\
\hline País/Provincia/Cantón & Ecuador/Carchi/Tulcán \\
Razón social & Productos Lácteos del Norte \\
Dirección & Calle Crespo Toral S/N de la ciudadela San Luis \\
Tipo de zona & Residencial \\
Área de la microempresa & $282 \mathrm{~m}^{2}$ \\
Números de empleados & 7 \\
Inicio de actividades & $01 / 2016$ \\
Tipo de industria & Alimenticia \\
Producción & $94 \%$ Quesos amasados y $6 \%$ cuajadas \\
Régimen de funcionamiento & Todos los días del mes/365 días al año \\
Materia prima consumida al día & 550 litros de leche \\
\hline Fuente: Elaboración propia basada en información de la microempresa Productos Lácteos del Norte
\end{tabular}

\subsubsection{Proceso productivo para la elaboración de queso amasado}

El queso amasado es el principal producto de la microempresa, representa el $94 \%$ de su producción. El proceso productivo para su elaboración consta de las siguientes etapas:
1. Recepción y bombeo de la leche.
6. Desuerado y molienda.
2. Pasteurización.
7. Amasado y salado. 
3. Enfriamiento y adición de calcio.

4. Coagulación.

5. Reposo y corte.
8. Moldeo y perchada.

9. Enfriamiento.

10. Empaquetado, sellado y almacenamiento.

El diagrama de flujo del proceso productivo del queso amasado se presenta en la Figura 1 , el cual indica las cantidades de materia prima e insumos utilizados mensualmente.

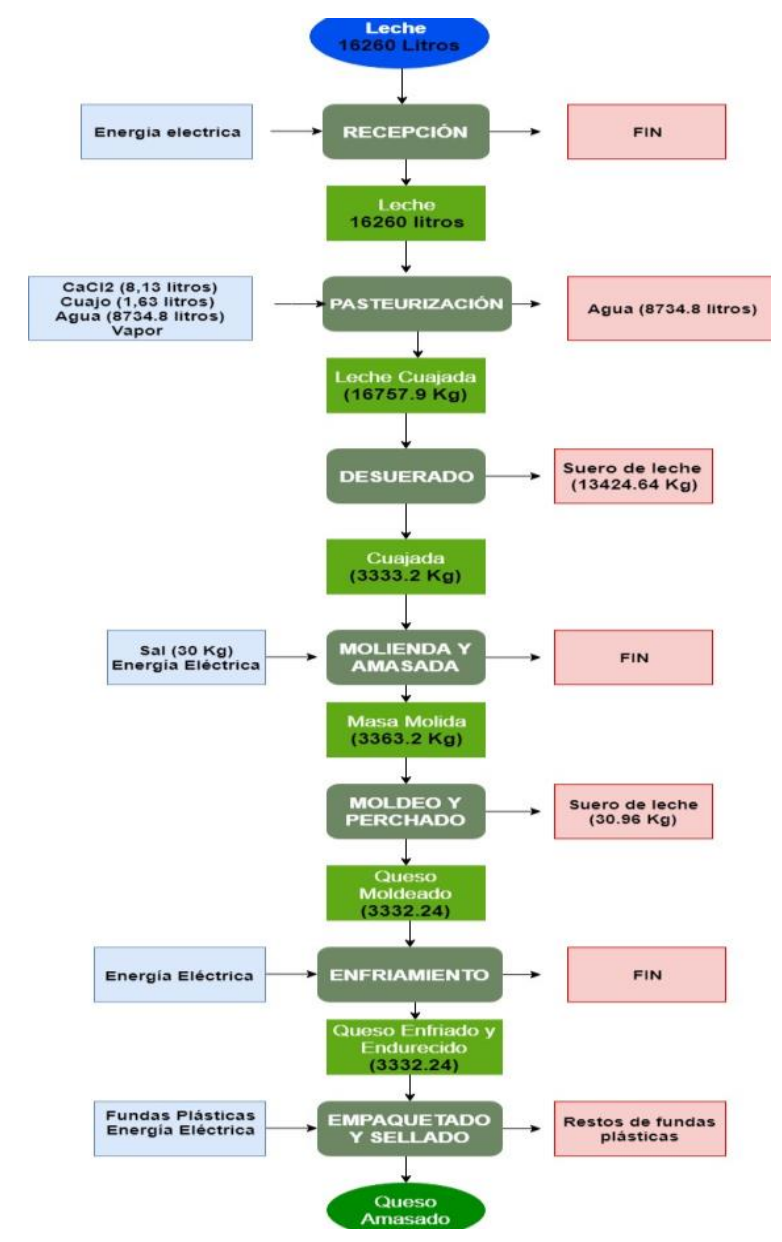

Figura 1. Diagrama de flujo del proceso productivo para la elaboración de queso amasado Fuente: Elaboración propia basada en información de la microempresa Productos Lácteos del Norte

\section{Prueba de laboratorio a las aguas residuales de la microempresa}

Tomando en cuenta el proceso productivo de la planta se tomó una muestra compuesta del agua residual generada en las etapas de moldeo y perchado. El agua residual se la recolectó antes de su ingreso a la red de alcantarillado, en la canaleta de salida ubicada en la planta.

Para realizar el ensayo fisicoquímico y microbiológico, se tomaron 2 litros de agua residual. En la Tabla 3 se muestra el resultado del ensayo realizado por el Laboratorio de Servicios Ambientales de la Universidad Nacional de Chimborazo. 
Tabla 3. Ensayo fisicoquímico y microbiológico de las aguas residuales

\begin{tabular}{lcc}
\hline PARÁMETROS & UNIDAD & RESULTADO \\
\hline $\mathrm{pH}$ & & 6,6 \\
Temperatura & ${ }^{\circ} \mathrm{C}$ & 30 \\
Conductividad & $\mu \mathrm{s} / \mathrm{cm}$ & 2660 \\
Sólidos Totales & $\mathrm{mg} / \mathrm{l}$ & 24688 \\
Sólidos Suspendidos & $\mathrm{mg} / \mathrm{l}$ & 4900 \\
Fosfatos & $\mathrm{mg} / \mathrm{l}$ & 4700 \\
Nitratos & $\mathrm{mg} / \mathrm{l}$ & 1140 \\
Nitritos & $\mathrm{mg} / \mathrm{l}$ & 4,3 \\
Cloruros & $\mathrm{mg} / \mathrm{l}$ & 6590 \\
DBO & $\mathrm{mg} / \mathrm{l}$ & 22600 \\
DQO & $\mathrm{mg} / \mathrm{l}$ & 27300 \\
Aceites y grasas & $\mathrm{mg} / \mathrm{l}$ & 1454 \\
Coliformes totales & $\mathrm{NMP} / 100 \mathrm{ml}$ & $<1$ (AUSENCIA) \\
Coliformes fecales & $\mathrm{NMP} / 100 \mathrm{ml}$ & $<1$ (AUSENCIA) \\
\hline
\end{tabular}

\subsection{FASE DE EVALUACIÓN}

En base a la evaluación de toda la información cuantitativa y cualitativa, el balance mensual del proceso productivo y la matriz FODA de la microempresa, se realizan las propuestas para la implementación de la estrategia ambiental PmL.

\subsubsection{Información cuantitativa del proceso productivo de la microempresa}

En la Tabla 4 se muestra la cantidad y costo de las materias primas e insumos requeridos en el proceso productivo para la elaboración de queso amasado.

Tabla 4. Cantidad y costo de las materias primas e insumos para la elaboración de queso amasado

\begin{tabular}{ccccc}
\hline $\begin{array}{c}\text { Materias Primas e } \\
\text { insumos }\end{array}$ & $\begin{array}{c}\text { Cantidad diaria } \\
(\mathbf{K g})\end{array}$ & $\begin{array}{c}\text { Cantidad } \\
\text { Mensual }(\mathbf{K g})\end{array}$ & Costo Unitario & $\begin{array}{c}\text { Costo Total } \\
\text { Mensual }\end{array}$ \\
\hline Leche & 559,3 & 16779,0 & $\$ 0,4$ & $\$ 6015,3$ \\
Cloruro de Calcio & 0,6 & 17,5 & $\$ 0,7$ & $\$ 12,9$ \\
Cuajo & 0,1 & 1,8 & $\$ 13,6$ & $\$ 24,4$ \\
Sal & 1,0 & 30,0 & $\$ 0,2$ & $\$ 5,7$ \\
TOTALES & $\mathbf{5 6 0 , 9} \mathbf{~ k g}$ & $\mathbf{1 6 8 2 8 , 3} \mathbf{~ k g}$ & $\mathbf{\$ 1 4 , 8}$ & $\mathbf{\$ 6 0 5 8 , 3}$ \\
\hline
\end{tabular}

Fuente: Elaboración propia basada en información de la microempresa Productos Lácteos del Norte

En la Tabla 5 se muestra el costo-consumo de agua, luz y diésel, tanto mensual como anual, que requiere la microempresa para realizar sus actividades productivas.

Tabla 5. Costo-consumo de agua, luz y combustible que requiere la microempresa

\begin{tabular}{ccccccc}
\hline \multirow{2}{*}{ Tiempo } & \multicolumn{2}{c}{ Agua } & \multicolumn{2}{c}{ Luz } & \multicolumn{2}{c}{ Diésel } \\
\cline { 2 - 7 } & $\mathrm{m}^{3}$ & Costo & $\mathrm{kW} \cdot \mathrm{h}$ & Costo & Galón & Costo \\
\hline Consumo medio mensual & 76 & 37,94 & 196 & 26,35 & 105 & 109,20 \\
Consumo mínimo mensual & 52 & 18,28 & 118 & 16,77 & & \\
Consumo máximo mensual & 114 & 75,45 & 354 & 45,75 & & \\
Consumo en el año 2017 & 909 & 455,25 & 2356 & 316,17 & 1260 & 1310,4 \\
\hline
\end{tabular}


Fuente: Elaboración propia basada en información de la microempresa Productos Lácteos del Norte

La Tabla 6 muestra la producción diaria y mensual de los productos principales y subproductos de la microempresa.

Tabla 6. Producción diaria y mensual de los productos principales y subproductos

\begin{tabular}{cccc}
\hline $\begin{array}{c}\text { Productos y } \\
\text { subproductos }\end{array}$ & Tipo & $\begin{array}{c}\text { Producción } \\
\text { diaria } \mathbf{( k g )}\end{array}$ & $\begin{array}{c}\text { Producción } \\
\text { Mensual }(\mathbf{K g})\end{array}$ \\
\hline Queso Amasado & Producto principal & $105,4 \mathrm{~kg}$ & $3162 \mathrm{~kg}$ \\
Cuajadas & Producto principal & $6.7 \mathrm{~kg}$ & $201 \mathrm{~kg}$ \\
Lactosuero & Subproducto & $437 \mathrm{~L}$ & $13110 \mathrm{~L}$ \\
\hline
\end{tabular}

Fuente: Elaboración propia basada en información de la microempresa Productos Lácteos del Norte

\subsubsection{Balance mensual del proceso de productivo}

En la Tabla 7 se presenta el balance mensual de los datos cuantitativos de las entradas y salidas del proceso productivo para la elaboración de queso moldeado o amasado.

Tabla 7. Balance mensual de los datos cuantitativos de las entradas y salidas del proceso

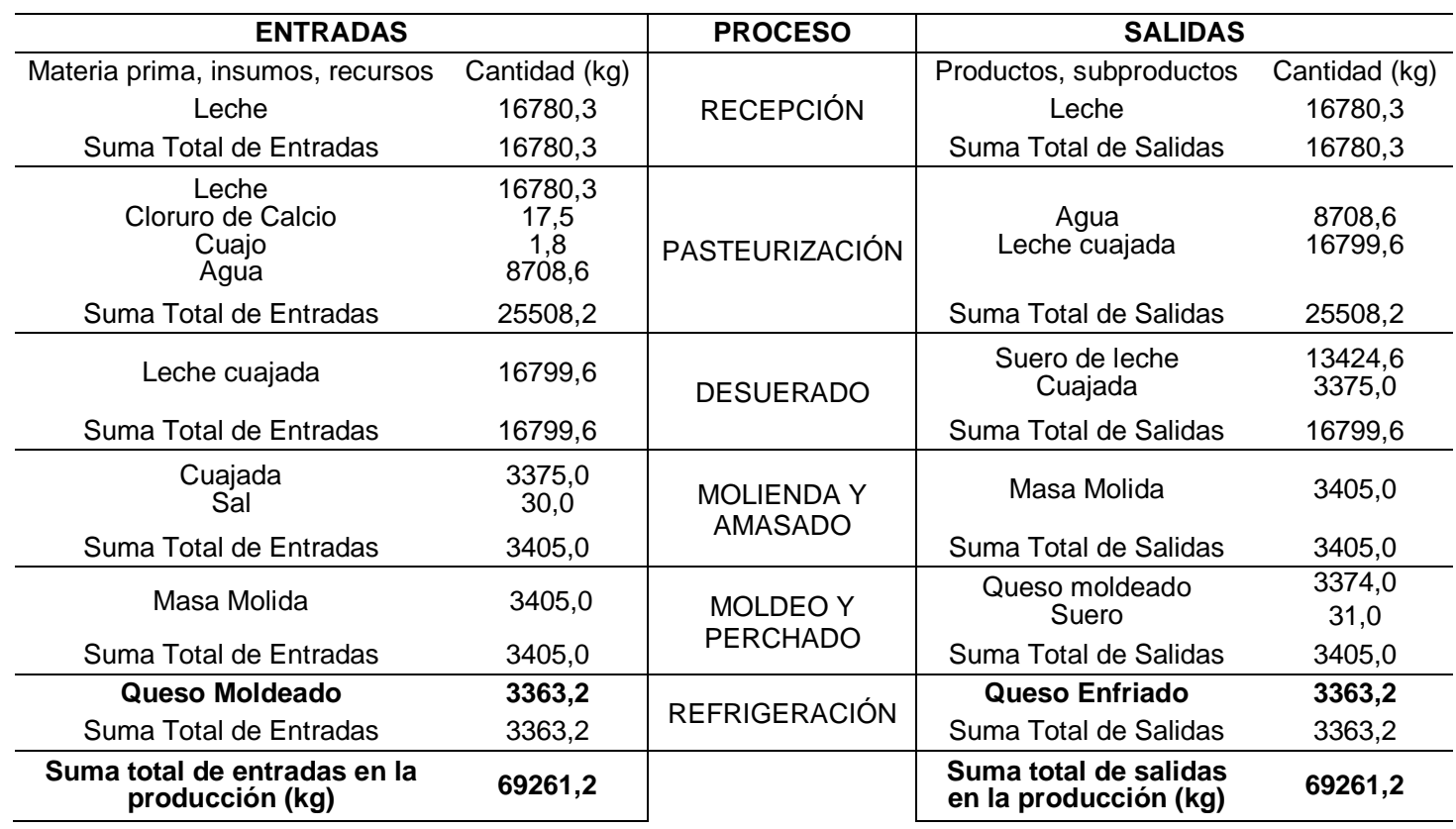

Fuente: Elaboración propia basada en información de la microempresa Productos Lácteos del Norte

\subsubsection{Matriz FODA de la microempresa}

Una vez que se ha estructurado toda la información de la microempresa se procedió a realizar la matriz FODA (Fortalezas, oportunidades, debilidades y amenazas) mostrada en la Tabla 8. Esta matriz se la utilizó como una herramienta de planificación y diagnostico estratégico que ayudó a la implementación de la estrategia ambiental PmL. 
Tabla 8. Matriz FODA de la microempresa

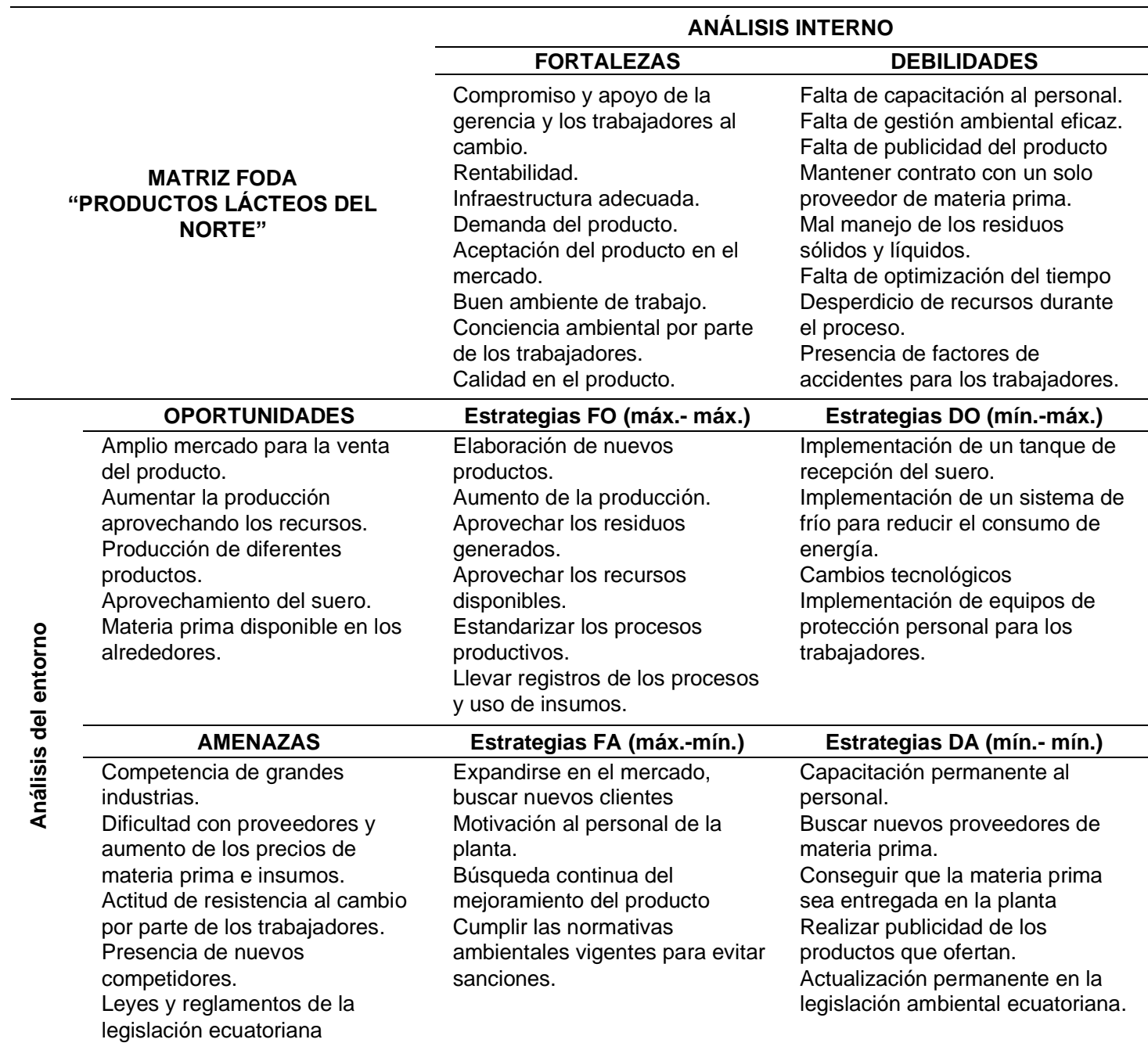

Fuente: Elaboración propia basada en información de la microempresa Productos Lácteos del Norte

\subsubsection{Propuestas para la implementación de la estrategia ambiental PML}

En base a la matriz FODA se sugirió que las siguientes propuestas generarían la oportunidad de implementar la estrategia PML, lo que beneficiara al medio ambiente y a la microempresa. La Tabla 9 muestra las propuestas para la implementación de la estrategia PML.

Tabla 9. Propuestas para implementación de la estrategia ambiental PML

\begin{tabular}{llll}
\hline $\mathbf{N}^{\circ}$ & \multicolumn{1}{c}{ Propuesta } & Ejecución & Beneficios \\
\hline 1 & Disminuir las pérdidas en el & Realizar capacitaciones para concientizar & Aumento de la productividad. \\
& proceso provocado por un al personal & Disminución de la carga \\
manejo inadecuado de & & contaminante en los efluentes. \\
& materia prima, insumos, & Cumplimiento de la legislación. \\
& productos y subproductos & &
\end{tabular}




\begin{tabular}{lll}
\hline 2 & $\begin{array}{l}\text { Estandarizar los parámetros } \\
\text { y los tiempos del proceso } \\
\text { productivo }\end{array}$ & $\begin{array}{l}\text { Llevar hojas de control de la cantidad de } \\
\text { materiales usados por lote de producción y } \\
\text { de los tiempos que se demora cada } \\
\text { proceso }\end{array}$ \\
\hline $3 \quad \begin{array}{l}\text { Remplazar los focos por } \\
\text { focos ahorradores (LED) }\end{array}$ & $\begin{array}{l}\text { Se debe realizar el cambio de los focos por } \\
\text { los tipos LED }\end{array}$
\end{tabular}

4 Aprovechamiento de la luz natural a través de la colocación de un calentador solar de agua
Invertir en la compra de un calentador sola de agua mostrando el ahorro que implica esta adquisición

Garantiza la calidad del producto ya que se respeta los estándares establecidos para la producción. Optimización de los recursos y equipos disponibles.

Disminución del consumo energético. Reducción en el pago de la planilla. Menos contaminación ya que no contiene mercurio y reduce emisiones de CO2. Larga en comparación con los otros tipos de lámparas.

Necesitan de un mínimo mantenimiento a diferencia de la caldera. Ahorro de energía y combustible. Seguridad al personal de la planta. Conservación de la calidad del aire y reducción de gases de efecto invernadero.

5 Aislar las tuberías de vapor Se debe realizar la inversión en el material que conducen el vapor e instalación del aislante de acuerdo a diámetro de la tubería

Reducción de las emisiones de CO2. Mayor control en los tiempos del proceso. Reducción del consumo de combustible. Rangos de presión estables en el sistema

6 Solicitar un medidor de tipo Acercarse a la empresa eléctrica industrial EmelNorte con los requisitos solicitados para el cambio de medidor

Reducción en el pago de planillas mensuales.

Cumplimiento de las leyes establecidas por consumo de energía. Evitar sanciones por parte de la autoridad competente.

7 Realizar la limpieza en seco Implementar una rejilla en la canaleta del de los residuos sólidos área de producción e invertir en escurridores de pisos para agilizar la recolección de los desechos. Supervisión continua.

8 Optimizar las operaciones Reutilización de agua proveniente del que consumen agua lavado de equipos, la cual puede servir para lavar pisos, patios, etc. Capacitar al personal en métodos de lavado y supervisión en el lavado. Evitar que los recipientes se llenen muy cerca o por encima de su nivel.

9 Control y reparación de Mantener vigilancia de las posibles fugas fugas de agua y que puedan presentarse, asignando a una mantenimiento de grifos, persona del personal como encargado. válvulas y tuberías

10 Instalación de un sistema de Se recomienda instalar un sistema de enfriamiento (Chiller) enfriamiento que disminuya la temperatura del agua del tanque que se utilizada en la pasteurización

11 Optimización del uso de agua mediante equipos de bajo volumen

Se recomienda instalar pistolas de cierre automático en las mangueras de lavado. Se puede cambiar los grifos por grifos de lavamanos provistos de aireadores 0 perlizadores que se enroscan en el grifo $y$ rompen el chorro de agua, logrando un mayor volumen del chorro. Permiten un ahorro del $40 \%$ de agua en los grifos tradicionales.

Evita accidentes laborales. Disminución de la carga contaminante.

Disminución del pago por consumo de agua. Cumplimiento de la legislación.

Ahorro económico en el pago de agua mensual. Reducción en el uso de este recurso

Reducción de costos por ahorro correctivo. Conservación del recurso agua. Ahorro económico en el pago del consumo de agua.

Reducción en la planilla del pago de agua.

Conservación del recurso agua. Reducción en el tiempo de producción

Aumento significativo en la eficiencia del consumo de agua. Reducción en el pago de la planilla por consumo de agua. Disminuye la demanda de agua. Reducción en los volúmenes de agua arrojados a la alcantarilla. Baja inversión.

Fuente: Elaboración propia basada en información de la microempresa Productos Lácteos del Norte 
Tabla 9. Continuación

\begin{tabular}{|c|c|c|c|}
\hline $\mathbf{N}^{\circ}$ & Propuesta & Ejecución & Beneficios \\
\hline 12 & $\begin{array}{l}\text { Implementación de un } \\
\text { tanque para almacenar el } \\
\text { suero mediante la } \\
\text { instalación de tubería que } \\
\text { envíe el subproducto de } \\
\text { manera directa al tanque } \\
\text { desde la marmita. }\end{array}$ & $\begin{array}{l}\text { Se recomienda la implementación de un } \\
\text { tanque de almacenamiento para el suero } \\
\text { de capacidad de } 300 \text { litros conectado } \\
\text { directamente a la marmita mediante } \\
\text { tubería. }\end{array}$ & $\begin{array}{l}\text { Disminución de la carga } \\
\text { contaminante en el efluente. } \\
\text { Disponibilidad de tiempo para } \\
\text { incrementar la producción. Evitar } \\
\text { el derrame de lacto suero por } \\
\text { trasiego manual. Reducción de } \\
\text { problemas ergonómicos en el } \\
\text { personal }\end{array}$ \\
\hline 13 & $\begin{array}{l}\text { Adquisición de una } \\
\text { enfundadora al vacío para el } \\
\text { producto }\end{array}$ & $\begin{array}{l}\text { Se sugiere implementar una } \\
\text { empaquetadora al vacío de quesos, lo que } \\
\text { generaría la posibilidad de salir del } \\
\text { mercado local. }\end{array}$ & $\begin{array}{l}\text { Mayor tiempo de vida útil del } \\
\text { producto. } \\
\text { Reducción en la generación de } \\
\text { residuos. Incrementación en la } \\
\text { calidad del producto. } \\
\text { Disminución del tiempo de } \\
\text { producción. }\end{array}$ \\
\hline 14 & $\begin{array}{l}\text { Capacitación al personal } \\
\text { sobre el manejo adecuado } \\
\text { de residuos sólidos }\end{array}$ & $\begin{array}{l}\text { Se deben realizar capacitaciones al } \\
\text { personal sobre el correcto desecho de los } \\
\text { residuos sólidos generados, los tipos de } \\
\text { tachos que existen y sobre el reciclaje. }\end{array}$ & $\begin{array}{l}\text { Disminuye la contaminación y } \\
\text { permite ahorrar recursos pues en } \\
\text { la basura se pueden encontrar } \\
\text { alternativas para sustituir o } \\
\text { reutilizar. } \\
\text { Evita la contaminación cruzada } \\
\text { de un desecho con otro } \\
\text { disminuyendo la propagación de } \\
\text { enfermedades. } \\
\text { Posibilidad de producir composta } \\
\text { con los residuos orgánicos. }\end{array}$ \\
\hline 15 & $\begin{array}{l}\text { Instalación de tachos } \\
\text { recolectores de basura para } \\
\text { cada tipo de residuo con su } \\
\text { respectiva señalética }\end{array}$ & $\begin{array}{l}\text { Se debe adquirir tachos de basura y } \\
\text { ubicarlos dentro de la planta para un } \\
\text { correcto desecho de los residuos. }\end{array}$ & $\begin{array}{l}\text { Disminuye la contaminación y } \\
\text { permite ahorrar recursos, ya que } \\
\text { algún tipo de desecho se puede } \\
\text { reutilizar. Evita contaminación } \\
\text { cruzada de un desecho con otro. } \\
\text { Se evita la producción de } \\
\text { composta con residuos } \\
\text { orgánicos. }\end{array}$ \\
\hline 16 & $\begin{array}{l}\text { Realizar capacitaciones al } \\
\text { personal }\end{array}$ & $\begin{array}{l}\text { Se debe planificar capacitaciones } \\
\text { periódicas y entrenamiento para el } \\
\text { personal de la planta. }\end{array}$ & $\begin{array}{l}\text { Incremento en la calidad del } \\
\text { producto. Manejo adecuado de } \\
\text { equipos. Reducción del riesgo de } \\
\text { accidentes. Disminución de la } \\
\text { contaminación. Cumplimiento de } \\
\text { la legislación. }\end{array}$ \\
\hline 17 & $\begin{array}{l}\text { Control de la producción } \\
\text { utilizando sistemas de } \\
\text { indicadores }\end{array}$ & $\begin{array}{l}\text { Diseñar hojas de registro para el control } \\
\text { de entradas y salidas del proceso, } \\
\text { identificando los puntos del proceso en } \\
\text { donde se debe llevar el registro escrito. }\end{array}$ & $\begin{array}{l}\text { Control de entradas y salidas del } \\
\text { proceso y cuantificación de los } \\
\text { costos de producción. } \\
\text { Disminución del riesgo de } \\
\text { pérdidas en la entrada de la } \\
\text { materia prima. Manejo de } \\
\text { indicadores reales } \\
\text { rendimiento por proceso de } \\
\text { producción. }\end{array}$ \\
\hline
\end{tabular}

Fuente: Elaboración propia basada en información de la microempresa Productos Lácteos del Norte

\section{Fase de estudio de factibilidad}

A continuación, se realiza el análisis de producción, consumo de energía y agua, aguas residuales, producción de residuos y propuestas para la implementación de PmL, con el objetivo de determinar la factibilidad para implementar la estrategia PmL en la microempresa.

\section{Análisis de la producción}

El principal producto elaborado es el queso amasado con un indicador del 94\%, seguido del $6 \%$ de cuajadas. El principal subproducto que resulta del proceso productivo es el suero de leche, el cual, de acuerdo al total de leche procesada representa el $81 \%$, lo que 
concuerda con lo estipulado por el Centro de Investigaciones Tecnológicas de la Industria Láctea, que indica que el suero representa entre el $80 \%$ y $90 \%$ del volumen total de la leche que se utiliza en el proceso e indica que este subproducto contiene el 50\% de los nutrientes de la leche original.

\section{Análisis del consumo de energía}

En el año 2017, como muestra la Tabla 5, se consumió $2356 \mathrm{~kW} \cdot \mathrm{h}$, pero, a partir del mes de octubre existió un mayor consumo de energía, debido a que en ese mes se instaló el congelador en el área de producción.

Se tiene un indicador de consumo de $115.3 \mathrm{~kW} \cdot \mathrm{h} /$ tonelada de queso, si se compara con el indicador promedio de la Guía de Aplicación de PmL en el sector Lácteo del CPML de Nicaragua que recomienda un valor de $211.11 \mathrm{~kW} \cdot \mathrm{h} /$ tonelada de queso, la planta industrial se encuentra dentro del consumo normal de energía.

La planta también utiliza diésel para los procesos de la caldera. Esta energía proveniente de hidrocarburos representa un alto costo, ya que la caldera consume 3,5 galones por día.

\section{Análisis del consumo de agua}

En el año 2017 se utilizó $909 \mathrm{~m}^{3}$ de agua para la producción de quesos, siendo las actividades de limpieza y enfriamiento de la leche, las que consumen mayor cantidad de agua. Tomando en cuenta el consumo promedio mensual de agua y los $\mathrm{Kg}$ de leche procesada, se tiene un indicador de consumo de 9,06 litros de agua / Kg de leche, que de acuerdo a la UNEP (Programa de las Naciones Unidas para el Ambiente) es un valor elevado, ya que esta institución recomienda un intervalo de 0,8 a 1 litro de agua / $\mathrm{Kg}$ de leche.

\section{Análisis de las aguas residuales del proceso productivo}

Al realizar la comparación de la Tabla 3 perteneciente al ensayo fisicoquímico y microbiológico de las aguas residuales con las Tablas de la Norma de calidad ambiental y de descarga de efluentes: Recurso agua Libro VI Anexo 1 (2000) se observa que los parámetros del ensayo no cumplen los límites permisibles, este hecho se debe principalmente a la presencia de lactosuero en las aguas de descarga, ya que el subproducto provoca el aumento en la $\mathrm{DBO}_{5}$ y DQO, según lo mencionado por CAR/PL (2002).

Sin embargo, los valores de temperatura, $\mathrm{pH}$, conductividad y sólidos suspendidos, según la Escuela de Organización Industrial (2008), están dentro de los rangos establecidos para aguas residuales que son generadas en industrias lácteas y productoras de quesos, mientras que los sólidos totales, nitratos, cloruros, fosfatos, $\mathrm{DBO}_{5}, \mathrm{DQO}$, aceites y grasas, sobrepasan los rangos. 


\section{Análisis de producción de residuos}

De acuerdo al análisis de residuos se tiene una producción per cápita de 1,8 kg de basura por habitante al día en la planta, Del total de basura generado, el mayor porcentaje es de plástico, ocupando el $40 \%$ del total generado, seguido del papel y cartón con un 34\%, y con un $26 \%$ los desechos orgánicos. Estos resultados concuerdan con lo señalado en la Guía de Aplicación de PML en el sector lácteo de Nicaragua, que indica que el mayor porcentaje de residuos producidos corresponden a residuos plásticos que son utilizados en el enfundado de queso.

\section{Análisis de las propuestas para la implementación de la estrategia ambiental PML}

Para las propuestas establecidas en la Tabla 9 se ha establecido un tiempo para su implementación. Este tiempo de implementación es a corto plazo, de 1 a 11 meses, a mediano plazo, de 1 a 2 años, y a largo plazo que es mayor a tres años.

En la Tabla 10 se realiza un análisis de las propuestas de la Tabla 9, con el objetivo de implementar estrategia ambiental PML en el proceso productivo de la microempresa Productos Lácteos del Norte. Para realizar el análisis se han evaluado aspectos como el tipo de oportunidad, rediseño de proceso, tiempo de implementación, etapa u operación, problemática ambiental, oportunidad de prevención de la contaminación, implantación, costo y beneficios de la implementación. A continuación, se presenta la Tabla 10. Análisis de las propuestas para la implementación de la estrategia ambiental PmL 
Tabla 10. Análisis de las propuestas para la implementación de la estrategia ambiental PmL

\begin{tabular}{|c|c|c|c|c|c|c|c|}
\hline 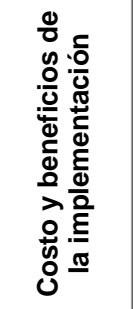 & 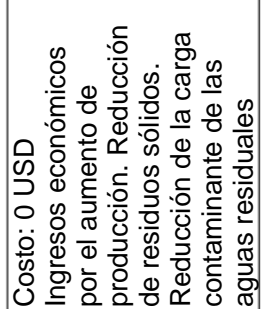 & 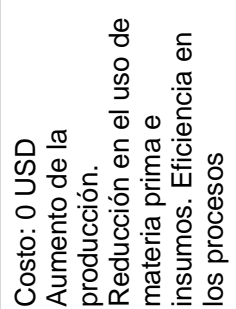 & 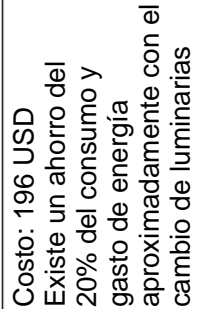 & 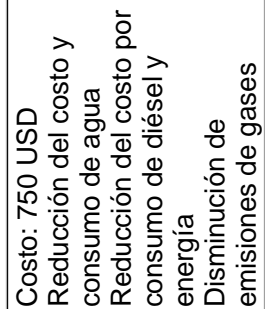 & 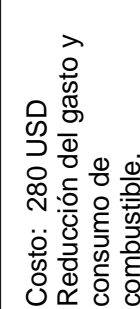 & 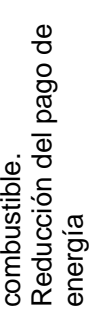 & 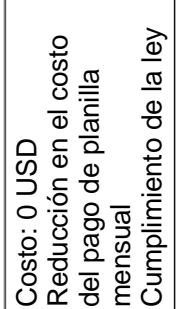 \\
\hline 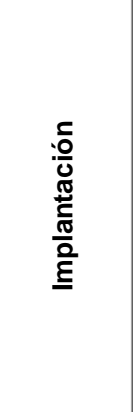 & 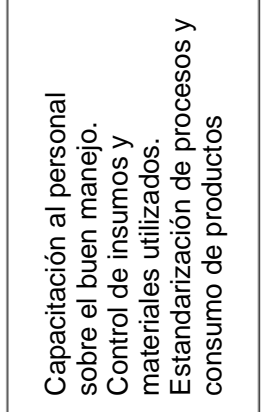 & 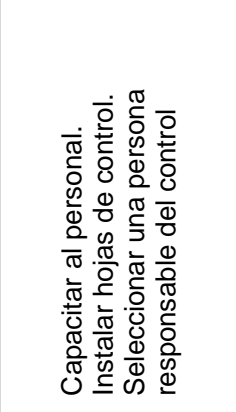 & 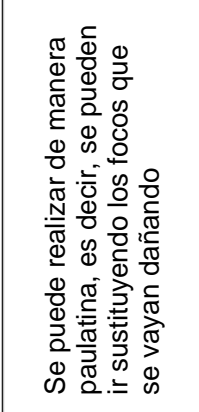 & 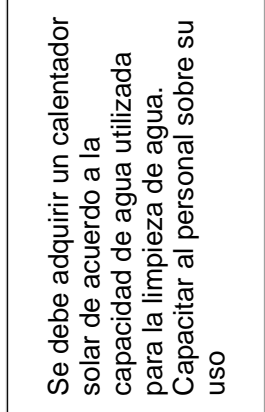 & 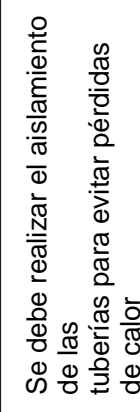 & 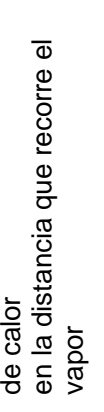 & 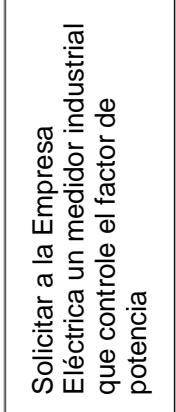 \\
\hline 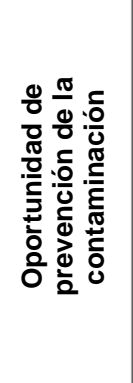 & 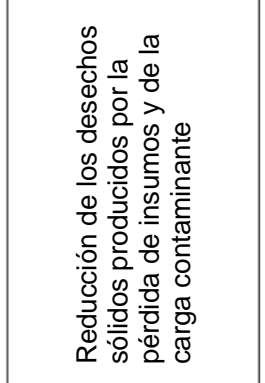 & 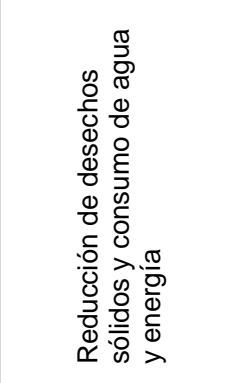 & 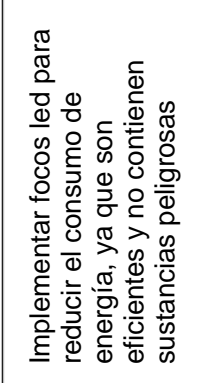 & 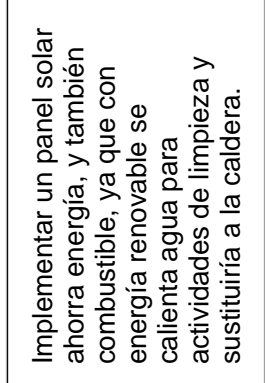 & 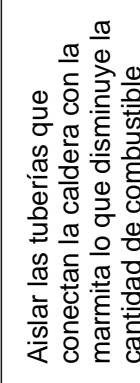 & 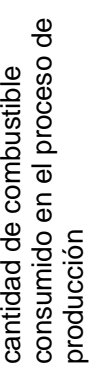 & 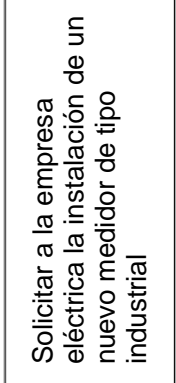 \\
\hline 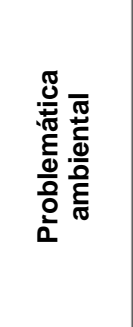 & 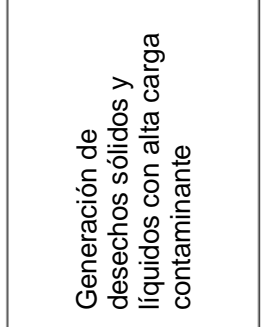 & 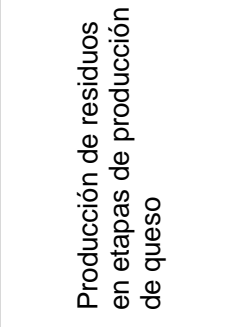 & 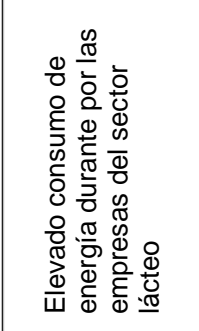 & 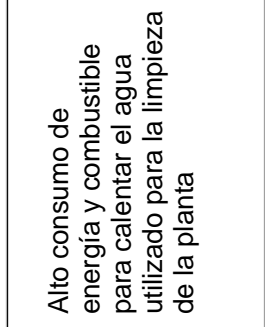 & 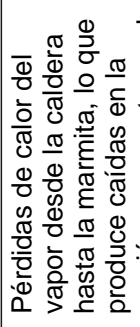 & 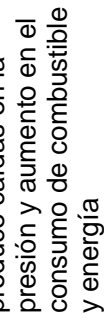 & 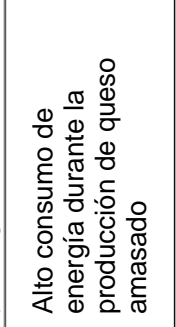 \\
\hline 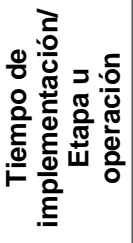 & 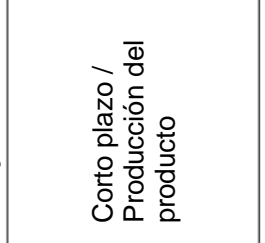 & 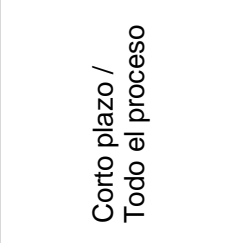 & 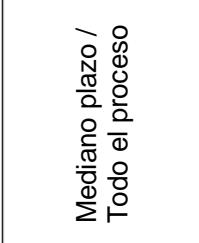 & 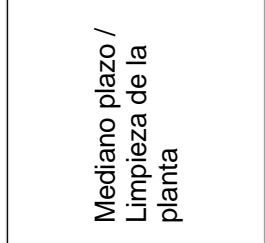 & 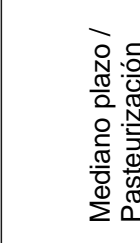 & 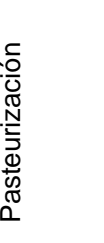 & 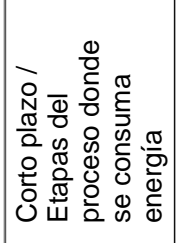 \\
\hline 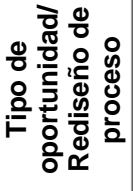 & 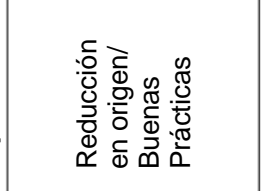 & 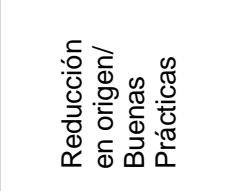 & 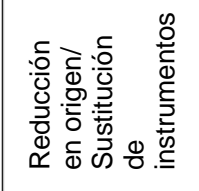 & 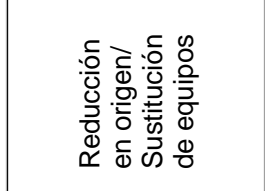 & 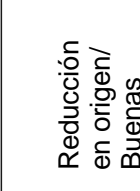 & 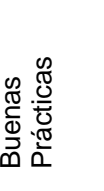 & 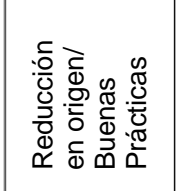 \\
\hline 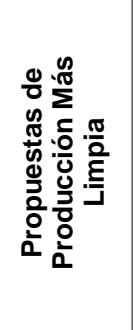 & 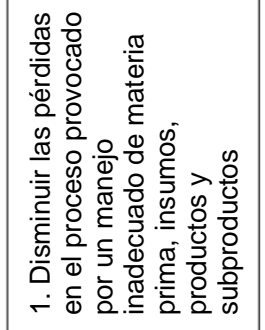 & 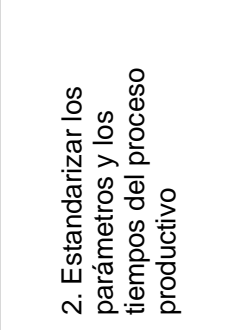 & 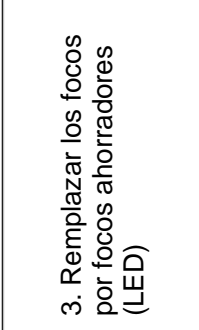 & 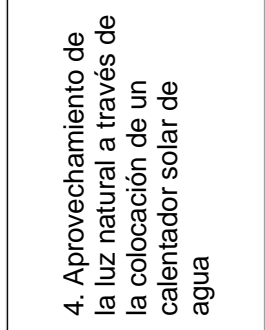 & 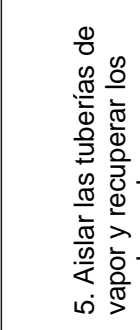 & & 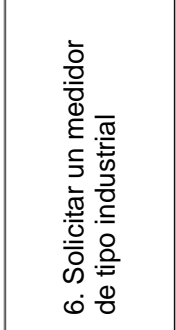 \\
\hline
\end{tabular}


Tabla 10. Continuación

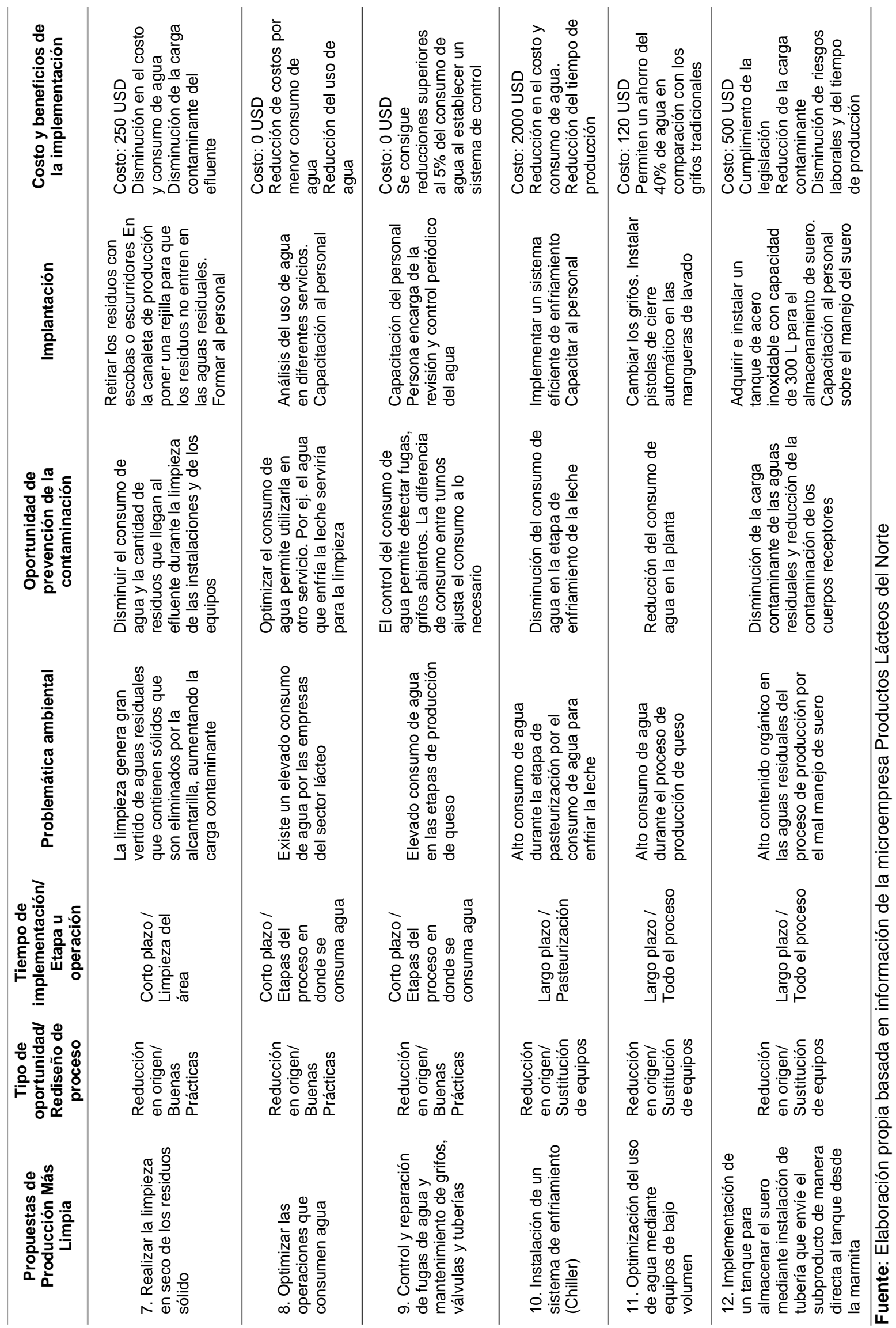


Tabla 10. Continuación

\begin{tabular}{|c|c|c|c|c|c|}
\hline 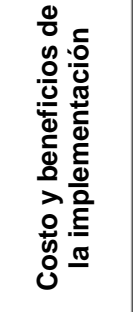 & 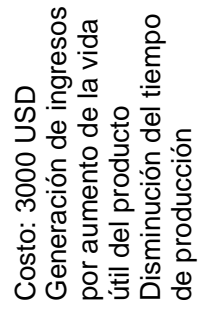 & 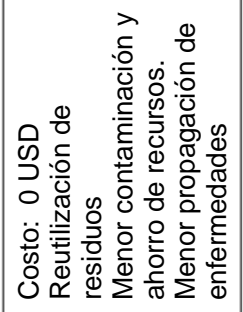 & 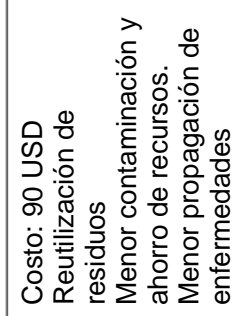 & 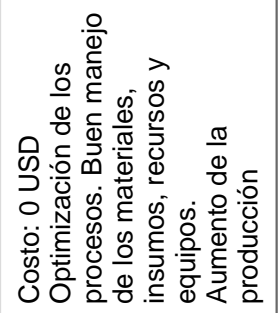 & 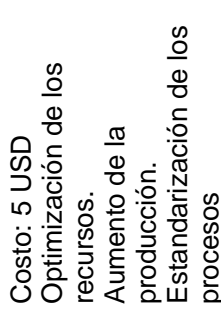 \\
\hline 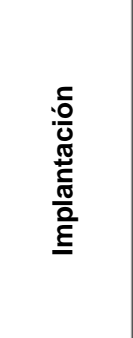 & 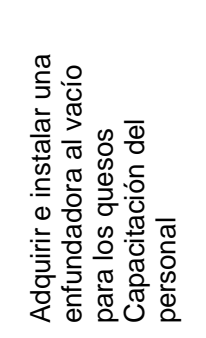 & 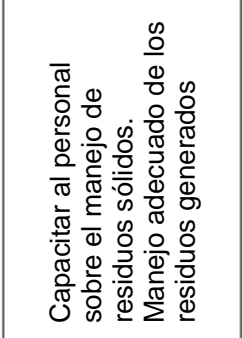 & 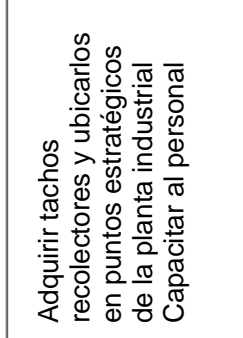 & 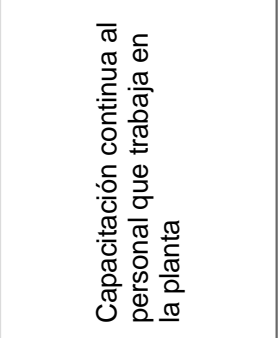 & 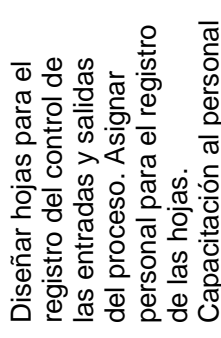 \\
\hline 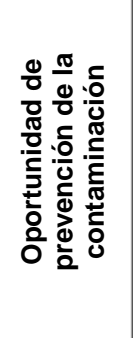 & 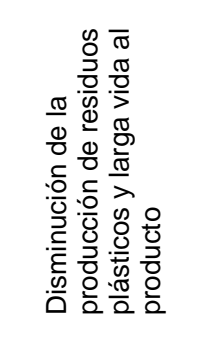 & 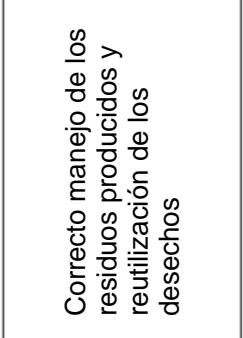 & 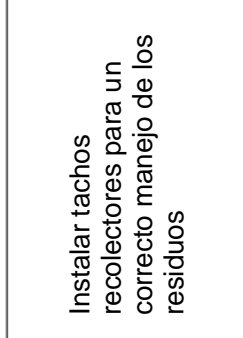 & 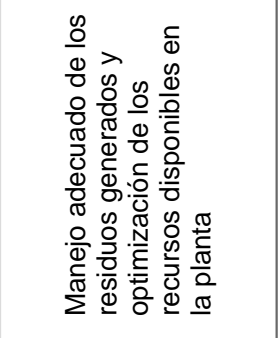 & 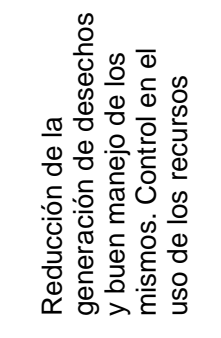 \\
\hline 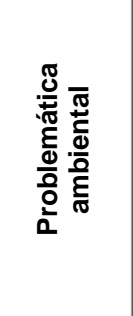 & 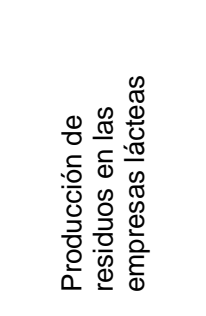 & 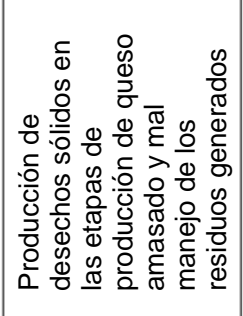 & 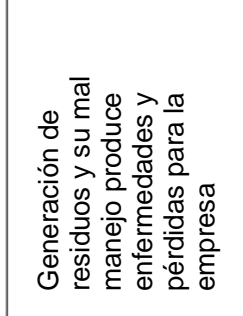 & 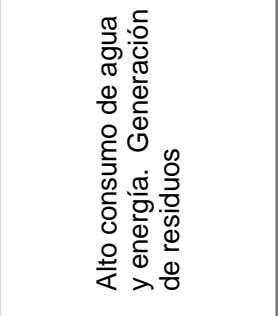 & 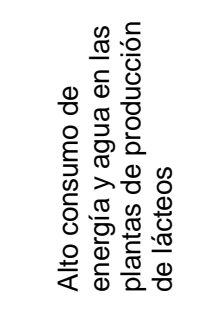 \\
\hline 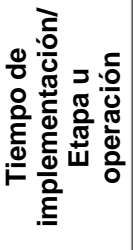 & 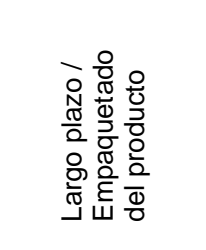 & 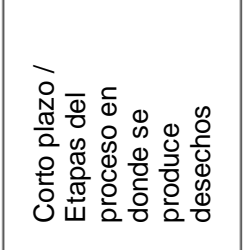 & 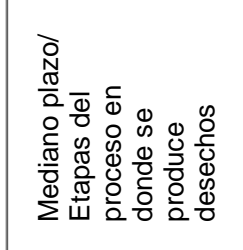 & 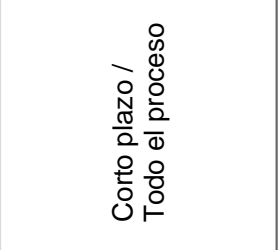 & 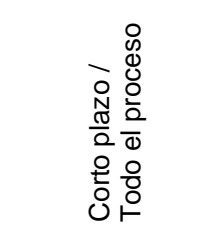 \\
\hline 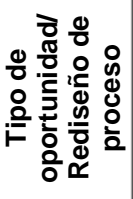 & 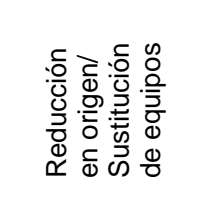 & 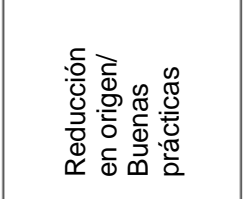 & 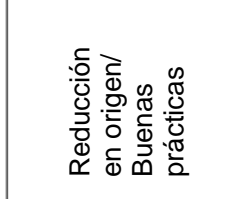 & 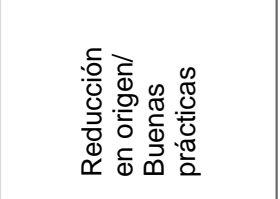 & 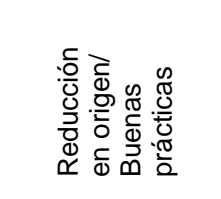 \\
\hline 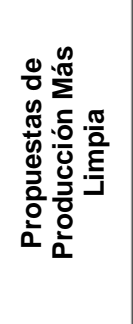 & 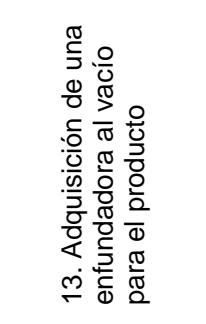 & 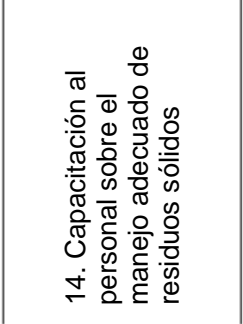 & 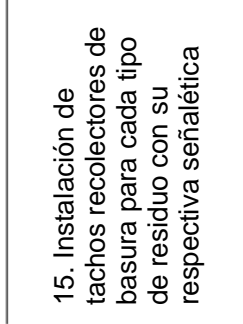 & 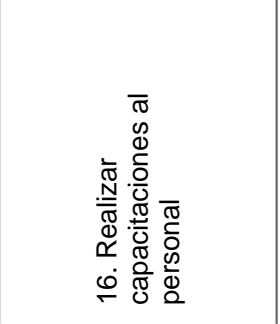 & 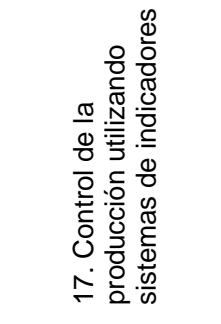 \\
\hline
\end{tabular}




\section{Resultados del estudio de factibilidad}

El análisis de producción muestra que los indicadores en porcentajes de queso amasado, cuajadas y suero, tienen una correcta relación con el porcentaje total de producción.

El análisis de consumo de energía muestra un indicador de $115.3 \mathrm{~kW} \cdot \mathrm{h} /$ tonelada de queso, el mismo que no supera el valor recomendado de $211.11 \mathrm{~kW} \cdot \mathrm{h} /$ tonelada de queso, por lo que el consumo de energía en la planta está dentro de lo normal.

En análisis de consumo de agua indica un elevado gasto de agua en el proceso de elaboración de queso amasado, el indicador de consumo tiene un valor de 9,06 L de agua / $\mathrm{kg}$ de leche en comparación del intervalo recomendado que es de 0,8 a 1,0 L de agua / $\mathrm{kg}$ de leche.

El análisis de parámetros físico-químicos y microbiológicos, muestra altos valores de $\mathrm{DBO}_{5}$, DQO y otras substancias más, en las aguas residuales.

El análisis de producción de residuos indica que la microempresa está dentro de los rangos permitidos.

El análisis de las propuestas establecidas en la Tabla 10, para la implementación de la estrategia ambiental PmL, fueron desarrolladas a través de los problemas encontrados en la fase de pre evaluación, fase de evaluación, y en los análisis pertenecientes a la fase de estudio de factibilidad. En el análisis de propuestas marca un camino para solucionar los problemas de producción y ambientales de la microempresa.

Mediante la ejecución de las propuestas de PmL a corto plazo, se logró mejorar el proceso de fabricación de quesos amasados, lo que permitió un ahorro económico y disminuir el impacto ambiental en la zona donde se encuentra la microempresa. Por lo que, si se ejecuta todas las propuestas a mediano y largo plazo, la factibilidad de consolidar la implementación de la estrategia ambiental PmL será viable.

\section{Conclusiones}

- Se implementó la estrategia ambiental PmL en la microempresa Productos Lácteos del Norte, sin embargo, la ejecución del análisis de propuestas a mediano y largo plazo se tendrán que ejecutar para la consolidación de la estrategia.

- Mediante la elaboración de la matriz FODA se identificaron las 17 propuestas para la implementación de la estrategia ambiental PmL.

- La implementación de la estrategia ambiental PmL logró mejorar el proceso de fabricación de quesos amasados, permitiendo un ahorro económico y minimizar el impacto ambiental en la zona donde se encuentra la microempresa.

- Los indicadores de producción porcentual, consumo de energía y consumo de agua, fueron comparados con otras fuentes de investigación, de esta forma al 
corregir los que están fuera del rango permitido, se gestionará eficientemente las materias primas e insumos.

\section{Referencias bibliográficas}

Alvarado, R. (2018). Estudio de Mercado "Sector de la leche en el Ecuador. Ecuador: Superintendencia de Control del Poder de Mercado. Recuperado de https://www.scpm.gob.ec/sitio/wp-content/uploads/2019/03/VP-ESTUDIO-DE-

LA-LECHE.pdf

Centro de Actividad Regional para la Producción Limpia (CAR/PL), Prevención de la contaminación en la Industria Láctea, 2002. Barcelona: ministerio de medio ambiente España

Centro de Producción más Limpia de Nicaragua. Guía de Aplicación de PmL en el sector Lácteo, 2008. Nicaragua: CPML. Recuperado de https://www.pml.org.ni/index.php/informese/publicaciones/file/38-guia-pmllacteos

Centro de Promoción de Tecnologías Sostenibles. Guía Técnica General de Producción Más Limpia, 2005. Bolivia: CPTS.

Escaño, L., Federico, E., Rivero, M., Baretta, L., \& Marchand, C. (2010). Guía práctica y estudios de casos producción más limpia Programa Buenos Aires Produce Más Limpio. Buenos Aires: Ministerio de Ambiente y Espacio Público. Recuperado de https://www.buenosaires.gob.ar/areas/med_ambiente/pol_ambiental/archivos/1.P roduccionMasLimpia_IndiceyPrologo.pdf

Escuela de Organización Industrial. (2008). Los vertidos del sector lácteo.

Hens, L., Block, C., Cabello-Eras, J. J., Sagastume-Gutierez, A., Garcia-Lorenzo, D., Chamorro, C., ... \& Vandecasteele, C. (2018). On the evolution of "Cleaner Production" as a concept and a practice. Journal of cleaner production, 172, 33233333.

Nunes, J. R. R., da Silva, J. E. A. R., da Silva Moris, V. A., \& Giannetti, B. F. (2019). Cleaner Production in small companies: proposal of a management methodology. Journal of Cleaner Production, 218, 357-366. Varela-Rojas, I. (2003). Definición de producción más limpia. Revista Tecnología En Marcha, 16(2), pág. 3-12. Recuperado https://revistas.tec.ac.cr/index.php/tec_marcha/article/view/1481

ODES. Lineamientos para el desarrollo de la producción más limpia como mecanismo de política en Corantioquia, 2002. Organización para el Desempeño Empresarial Sostenible, Medellín. 
Pardillos, M. (2020). El mercado del queso en Ecuador. Quito: ICEX España Exportaciones e Inversiones.

Republica de Ecuador. Norma de calidad ambiental y de descarga de efluentes: Recurso agua Libro VI Anexo 1, 2000. Ecuador

Revista Líderes. (16 de febrero de 2015). Un tercio de la producción láctea se dedica al queso. Recuperado de https://www.revistalideres.ec/lideres/ecuador-produccionlactea-queso.html

Rodríguez, A., Samayoa, A., Calderón, M., \& Rodríguez, A. (2019). Curso de Producción más Limpia (PmL) como herramienta para el Manejo Integrado de Cuencas. Centro Guatemalteco de Producción más Limpia (CGP+L)

Tinoco, O. (Ed.)., \& Armijo, J. (2019). GESTIÓN Y PRODUCCIÓN MÁS LIMPIA: UN PARADIGMA VIGENTE.

Uguña, M. (2010). Estudio del comportamiento de las variables de Producción Más Limpia en las haciendas lecheras modelos de las parroquias Tarqui y Victoria del Portete del Cantón Cuenca Provincia del Azuay (Tesis de Maestría). Universidad de Cuenca. Ecuador.

Van Hoof, B., Monroy, N. \& Saer, A. (2008). Producción más limpia. Paradigma de gestión ambiental. Colombia: Alfaomega Colombiana S.A.

\section{LCiencia}




\section{PARA CITAR EL ARTÍCULO INDEXADO}

Nuñez Moreno, M. S. (2021). Implementación de la estrategia ambiental Producción más Limpia (PmL) para el proceso productivo de la microempresa Productos Lácteos del Norte . AlfaPublicaciones, 3(2.2), 28-49. https://doi.org/10.33262/ap.v3i2.2.57

\section{\Ciencia}

El artículo que se publica es de exclusiva responsabilidad de los autores y no necesariamente reflejan el pensamiento de la Revista Alpha Publicaciones.

El artículo queda en propiedad de la revista y, por tanto, su publicación parcial y/o total en otro medio tiene que ser autorizado por el director de la Revista Alpha Publicaciones.
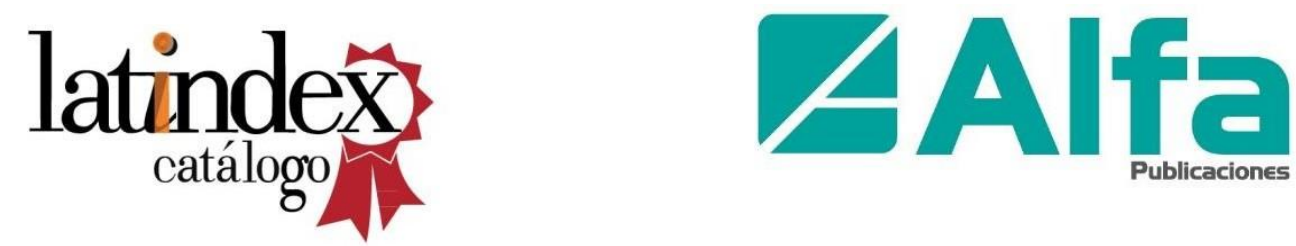